\title{
The Development of Scaling Table about Inner Social Capital in Technology Innovation Team and the Test of Its Reliability and Validity
}

\section{-Based on Empirical Analysis of Technology Innovation Teams in Agriculture Industry of Sichuan Province}

\author{
Liyu $\mathrm{Ju}^{1} \&$ Xinhong $\mathrm{Fu}^{1}$ \\ ${ }^{1}$ College of Economics and Management, Sichuan Agricultural University, Chengdu 611130, Sichuan, China \\ Correspondence: Xinhong $\mathrm{Fu}$, College of Economics and Management, Sichuan Agricultural University \\ Chengdu Campus, Chengdu 611130, Sichuan, China. Tel: 86-139-8161-1038. E-mail: xinhongf@sina.com
}

Received: April 23, 2012 Accepted: May 8, 2012 Online Published: July 11, 2012

doi:10.5539/jas.v4n8p124 URL: http://dx.doi.org/10.5539/jas.v4n8p124

The paper is sponsored by project: The integration of agricultural industrial chain and technology chain in Sichuan province.

\begin{abstract}
This paper is based on the definition of social capital and technology innovation team. The related theory of social capital, especially the study about inner social capital in team is reviewed. A scaling table about inner social capital in technology innovation team including 25 items is developed initially. 95 valid questionnaires are collected about technology innovation teams in agriculture industry of Sichuan province. The method of item analysis, the test of reliability and validity are adopted. Finally, three constructs including 16 items are kept to form the scaling table.
\end{abstract}

Key words: technology innovation team, inner social capital, scaling table, reliability, validity

\section{Introduction}

The theory of social capital is considered to be one of the most influencing theories since $20^{\text {th }} 90$ (Woolcock $\&$ Narayan, 2000). Even in economics considered to be the most exclusive area, the concept of social capital is going to be accepted (Yanjie Bian, 2006), and the theory of social capital is one of the main theories in organizational management (Jiangqiu Wu, 2009). Nahapiet and Ghoshal (1998) state that organization as one of system circumstances can be helpful to the production of social capital. It is helpful to generate new intellectual capital by promoting the exchange and combination of intellectual capital. The interaction of the both make the organizations' competitive advantage consolidated. This is one of the classic studies in the theory of social capital. Leana and Van Buren (1999) research social capital from the level of organization. They thought social capital of organization can strengthen the common goal, promote the generation of trust, and promote the more successful collective action to create value.

Through the literatures' review, we can find that the research of social capital in organizational management is focused on the company (Tsai \& Ghoshal, 1998; Yanjie Bian \& Haixiong Qiu, 2000; Fanghua Zhang, 2006; Hongming Xie, Cheng Wang \& Yechun Wu, 2007). Only a few scholars studied the social capital about group or team (Roseenthal, 1996; Jianglin Ke, Jintao Shi \& Jianmin Sun, 2007). The development of scaling table is the basis of empirical analysis about social capital. Jianglin Ke et al (2007), Can Peng and Jinxi Li (2011) study on the development of teams' scaling table. Because of the own debate of social capital (Wenhong Zhang, 2003) and the difference of measuring tool, the scaling table should be moderate to different kinds of teams (Jianglin Ke et al, 2007). This paper will develop scaling table about inner social capital in technology innovation team and test its reliability and validity.

\section{The Definition of the Concepts}

\subsection{Social Capital}

Until now, there is no general definition about social capital. Scholars give different definition from different angels. The definitions given by Pierre Bourdieu, James S. Colman, Alejandro Portes and Ronald Burt are 
influencing. Lin Nan took both members' relationship and structure of the network into consideration and put forward the theory of "social resources" making basis of the theory of social capital. He thinks that social capital can be defined as one of the social resources embedded in social structure and can be used or mobilized in some activities with purpose. That is to say the concept of social capital contains three components: resource embedded in social structure, the persons' capability to use the resource and through the objective ability to use or mobilize these resources.

In the area of organizational management, Nahapiet and Ghoshal (1998) define the social capital as the sum of the potential and real resource embedded in the network owned by individual or organization. Wayne Baker (2000) thought that social capital is resource gotten from interpersonal relationship or enterprise network, including information, conception and the clues, business opportunities, financial capital, power and influence, emotional support and even the good wish, trust and cooperation. Cohen and Prusak (2001) think social capital includes trust, bilateral understanding, shared values and behavior making positive contact possible and constraining persons' action to make cooperation possible.

In China, Yanjie Bian and Haixiong Qiu (2000) define social capital as contact between the main body and the society, the capability to access resource through the contact. From the above, we can see that the definition of social capital in organizational management is more or less based on the definition made by Lin Nan. So in this paper the social capital is defined as the resource embedded in social structure can be mobilized and accessed by people.

\subsection{Technology Innovation Team}

There is no general definition about technology innovation until now. Scholars define it from its narrow sense and broad sense, for example, Mansfield (1971) defines it as the first application of an invention, it is the first time to import a new kind of products or process containing various steps such as technology, design, production, finance, management and market. The broad sense can be seen from J. L. Enos (1962). He defined technology innovation as the result of several behaviors' composition. These behaviors include the choice of invention, guarantee of capital investment, establishing organization, planning, hiring workers, opening markets and so on. Xielin Liu (1993) thinks that technology innovation is technology, designing, manufacturing and commercial activities related to the first commercial application of new products, new process and equipment. It includes the innovation and diffusion of the products and process. Jiaji $\mathrm{Fu}(1998)$ defines it as the process that entrepreneurs take potential market opportunities, get the business interests as the goal, organize production conditions and factors, set up more strong, higher efficiency and lower cost production and operation system, put out new products, new manufacturing process, open new markets, get new sources of raw materials or semi-finished products or establish new enterprise organization. It is the integrated process including a series of activities, such as science and technology, finance, business and organization.

This paper combines definition above and the characteristics of the studied object, the definition of technology innovation is from broad sense. Technology innovation is a series of recycling, rising process. Its main body is enterprise, taking the market demand as the guide, making the combination of enterprises, universities and scientific research institutions as innovation system, agglomerating good production elements, innovating organization mode, accessing new sources of raw materials, introducing new technology, new production method and mode of production and new products, establishing new production procedure, exploring new marketing mode and opening new market. So we can see that the subjects of technology innovation include enterprises, scientific research institutes and colleges. Technology innovation team is formed for the purpose of technology innovation. Its members are from enterprises, scientific research institutes and colleges. They are members of the three units as well as the team members.

\section{The Measurement of Technology Innovation Teams' Social Capital}

Different scholars take different index in the measurement of social capital because of the different definition. From the review below, we can see there are researches about the hierarchies, dimensions and indexes of social capital, especially research about inner social capital in technology innovation team. The measurement of inner social capital in technology innovation team in this paper will base on them.

\subsection{The Hierarchies of Social Capital}

There are three kinds of social capital hierarchies. The first is individual social capital and group social capital. Coleman and Lin Nan are the representatives of individual social capital. Putnam is the pioneer of group social capital. The object in this paper is belonging to the scope of group social capital. The second is micro social capital, medium social capital and the macro social capital divided by Brown, Tomas Ford and Turner, Jonathan H. All the research taking organization as the basic analysis unit of social capital belongs to medium social 
capital (Wenhong Zhang, 2003). The third is inner social capital and outer social capital divided by Adler and Kwon (2002). Outer social capital is called bridged social capital, which arises from the social networks of outer actors. It is the sum of resources embedded in the outer network. Inner social capital is called related social capital, which exists in groups or organizations. It is the sum of actual and potential resources embedded in the inner social networks. In the study of teams' social capital, Jianglin Ke, Xiaotao Zheng and Jintao Shi (2006) develop the scaling table of research and development teams' inner social capital. This paper will also develop the scaling table of technology innovation teams from this angle.

\subsection{The Dimensions of Social Capital}

There are usually two kinds of methods to divide the dimensions of social capital. Uphoff (1996) points out that social capital influences things through two different types of it. They are structural social capital and cognitive social capital. The former is relatively objective, and the performance is visible. It may be designed or improved by conscious action of the group. The latter reflects people's thoughts and feelings, so they are more subjective and difficult to change. Nahapiet and Ghoshal (1998) form the theory frame of organizations' social capital from three dimensions: the structural, relational and cognitive dimensions. The structural dimension of social capital is known as the structural embeddedness, emphasizing the whole contacting mode among actors, reflecting the impersonal aspect of social network, while relational and cognitive dimensions reflecting the personal aspect of social network. In the study of teams' social capital, Jianglin Ke, et al (2006), Na Zhang, Xuezhong Chen (2007) and Mingqing Qin (2010) adapt this method to analyze the teams' social capital. The way of three dimensions is more clear, comprehensive and used extensively. But scholars often take different measurement indexes for different objects. So in this paper the scaling table of social capital will be developed and tested for technology innovation teams.

\subsection{The Selection of Measure Indexes}

In the research of social capital, trust is one of the important measure indexes of social capital. Francis Fukuyama (1998) takes trust as the only index of social capital, Putnam (2001) defines social capital as the certain features of social organization, such as the trust, norms and network. Adler S. Paul and Kwon S. (2002) considers that sympathy, trust and tolerance are important parts of the relationship. Uphoff (1996) uses the role and social network to measure structural social capital, the standard, values and beliefs to measure cognitive social capital. Nahapiet et al (1998) mainly use the network ties, network configuration, and appropriate organization to measure the structural social capital. Trust, norms, obligations and identification are used to measure the relational social capital. The cognitive social capital is measured by shared codes, language and shared narratives.

Some scholars in China also use the three dimensions of social capital made by Nahapiet et al (1998), such as Jun You, Bin zhang (2010), but the indexes are different. In the research made by Yi Guo, Xi zhu (2003), as long as the inner part of organization is concerned, the structure of network, the trust among the members and the shared goals determine the level of social capital. Three dimensions separately turn out to be interpersonal network and characteristics in the organization, trust and other relations, sharing language and tacit knowledge (It should also includes the shared values and meaning system among members generally).

In the research of teams' inner social capital, Yiming Lin (2001) studied on the social capital of team. He adopted communication frequency and the degree of informal interaction to measure the structural dimension, the overall trust to measure the relational dimension, the shared value to measure the cognitive dimension. Fangrong He (2003) adopted social interaction, the network position, relationship quality and cognitive network to measure social capital of the team. Jianglin Ke et al (2006) study on it and develop the scaling table of teams in enterprise. He measures the interaction among team members from the vertical and the horizontal (structural social capital). The vertical is measured by interaction frequency, while the horizontal is measured by network density. The relational social capital is represented by trust. There are vertical trust and horizontal trust in the team, respectively measured by colleagues trust and leader trust. Cognitive social capital is divided into structural cognition and component cognition. The former is measured by shared vision and the latter is measured by shared language. Na Zhang et al (2007) divide social capital into inner, central and outer social capital. Inner social capital is measured by the classical three dimensions. Structural dimension is measured by communication and interaction; Relational dimension is measured by trust and norms; the cognitive dimension is measured by shared values.

There are individual central network and the whole network methods in the quantitative measure of social network and social capital. The method of the whole network is mainly used for the analysis of internal relations in organizations (Wenhong Zhang, 2011). The formation and development of social capital is influenced largely by background of countries or regions, such as society, economy and culture, and different indexes should be 
chosen to measure different objects. Through the literature review, there are few specific researches on development of scaling table about inner social capital in technology innovation team (As defined in this paper). In this paper, the quantitative method of whole network is adopted, combining with the research above and the characteristics of the technology innovation teams to choose measure indexes. The inner network structure is measured by connection status, the center of network and teams' stability. The connection status is used to measure the frequency of formal and informal interaction among members; the center of network measures the degree of centralization in the team; it is the degree of interaction and resources concentrated on a few persons. The degree can not be too low or too high in a group (Jun You et al, 2010); Teams' stability measures the stability of social capital' existence. Social capital' existence relies on network, so the frequent change of members will do harm to the team. The selection of indexes above is inseparable with the characteristics of technology innovation team. The members of the team mostly come from multiple organizations. Keeping the stability of the team members, forming united and closely linked characteristics are important to the existence and development of the team. The personal aspect of teams' inner social capital is measured by trust, obligations and expectations, shared language and shared goal. The trust is divided into leader trust and members trust (Jianglin Ke et al, 2006). Using "shared goal" instead of "shared vision" to measure the team members' common idea makes the question more practical.

\section{The Empirical Analysis of Scaling Table about Inner Social Capital in Technology Innovation Teams}

\subsection{Tools and Data Source}

\subsubsection{Tools}

The scaling table is preliminary formed after reading related literature and doing depth interview. After discussing with teachers and the graduate students who have questionnaire designing experience and are engaged in the research, a preliminary scaling table containing 25 items is formed. The items can be seen in table 1 . Items' evaluation is used Lirkert 5 point scaling method. The evaluation is from "completely disagree" to "completely agree ".

Table 1 . The preliminary scaling table about inner social capital in technology innovation teams

\begin{tabular}{|c|c|}
\hline connection status & $\begin{array}{l}\text { A11 Team members often talk about research by the way of meeting } \\
\text { A12 Team members often organize activities } \\
\text { A13You often communicate with other members of the team by phone, email, QQ and so on. }\end{array}$ \\
\hline center of network & $\begin{array}{l}\text { A21 The team leader has high influence in the team } \\
\text { A22 The team leader master more resources in the team } \\
\text { A23 The team leader has great influence on the decision of the team } \\
\text { A24 Not only one person has great influence on the decision of the team }\end{array}$ \\
\hline teams' stability & A31 Team members are relatively stable \\
\hline leader trust & $\begin{array}{l}\text { A41 The team leader has the ability to assume his responsibility } \\
\text { A42 The team leader can treat team members fairly } \\
\text { A43 The team leader is honest and credible } \\
\text { A44 There is information provided by the team leader, but sometimes it turns out not to be accurate later }\end{array}$ \\
\hline members trust & $\begin{array}{l}\text { A51 Team members can keep promise for each other } \\
\text { A52 Members trust the ability of each other in working } \\
\text { A53 Most members of the team can do what they say } \\
\text { A54 There is information provided by the members, but sometimes it turns out not to be accurate later }\end{array}$ \\
\hline $\begin{array}{l}\text { Obligations and } \\
\text { expectations }\end{array}$ & $\begin{array}{l}\text { A61 Team members can actively assume their duties and obligations } \\
\text { A62 Team does reasonable expectations to the members, making clear mechanism of rewards and } \\
\text { punishments } \\
\text { A63 Team members will abide by the principle of reciprocity. One can get the corresponding returns } \\
\text { lately }\end{array}$ \\
\hline shared language & $\begin{array}{l}\text { A71 You can well understand the terminology used by other members of the team } \\
\text { A72 You are very familiar with the software used in working and the working process in the team } \\
\text { A73 You can communicate with team members freely, without language barriers }\end{array}$ \\
\hline Shared goal & $\begin{array}{l}\text { A81 You know clearly about stage goal of the team, and have high approval with the goal of the team } \\
\text { A82 You know the prospect of the team very well and have high approval with it } \\
\text { A83 When personal goal conflict with the team goal, you can adjust your personal goal to adapt the } \\
\text { team goal }\end{array}$ \\
\hline
\end{tabular}

Note: The teams in the scaling table are technology innovation teams. 


\subsubsection{Data Source}

The data used in this paper is from investigation of technology innovation teams of agricultural industry in Sichuan province. In June 2009, the Science and Technology Bureau in Sichuan province initiated the project called technology innovating industrial chain. Agricultural industry technology innovation teams are formed by members from agricultural industry enterprises with advantage, universities and scientific research institutions. The technology chain is constructed to support and extend industry chain. In every industry there are a chief expert and a presided enterprise to manage the technology innovation teams. In October 2011, the first six industrial chains were checked. From December 2011 to March 2012, technology innovation teams in three industrial chains (pig, pickles, edible fungus) were investigated. 152 questionnaires are given out, 96 questionnaires are taken back, including 95 effective questionnaire. The rate of questionnaires' taken back is $63 \%$, and the rate of effective questionnaire is $99 \%$.

\subsection{Item Analysis}

The main purpose of item analysis is to judge the discrimination of items, work out the items' critical ratio value-the value of $\mathrm{CR}$, and delete the item not to achieve significant level. According to the analysis steps, first of all, do reverse scoring for the reverse items, calculate the total score and range them in descending order, to determine the high and the low scores in the $27 \%$ point of the group, by which the observations will be divided into two groups. T-test will be used to determine whether the item has the ability of discrimination. In the results, "equal variance assumed" should be seen first, if it is significant (the value of the sig. is less than 0.05), and then see the value of " $\mathrm{t}$ " in the "equal variance not assumed" column, if it is significant (the value of the sig. is less than 0.05 ), then the item has discrimination. If the value of " $\mathrm{F}$ " is not significant (the value of the sig. is more than 0.05 ), then see the value of " $t$ " in the "equal variance assumed" column, if it is significant (the value of the sig. is less than 0.05), then the item has discrimination (Minglong Wu, 2003). Test results are shown in Table 2

Table 2. Independent sample T-test

\begin{tabular}{|c|c|c|c|c|c|c|c|c|c|c|}
\hline Items & & $\mathrm{F}$ & Sig. & $\mathrm{t}$ & Sig.(2-tailed) & Items & $\mathrm{F}$ & Sig. & $\mathrm{t}$ & Sig.(2-tailed) \\
\hline \multirow[t]{2}{*}{ A11 } & $\mathrm{a}$ & 61.685 & 0.000 & 4.463 & 0.000 & A12 & 94.118 & 0.000 & 11.111 & 0.000 \\
\hline & $\mathrm{b}$ & & & 4.463 & 0.000 & & & & 11.111 & 0.000 \\
\hline \multirow[t]{2}{*}{ A13 } & $\mathrm{a}$ & 96.531 & 0.000 & 5.508 & 0.000 & A21 & 112.558 & 0.000 & 4.900 & 0.000 \\
\hline & $\mathrm{b}$ & & & 5.508 & 0.000 & & & & 4.900 & 0.000 \\
\hline \multirow[t]{2}{*}{ A22 } & $\mathrm{a}$ & 36.358 & 0.000 & 6.022 & 0.000 & A23 & 44.888 & 0.000 & 8.223 & 0.000 \\
\hline & $\mathrm{b}$ & & & 6.022 & 0.000 & & & & 8.223 & 0.000 \\
\hline \multirow[t]{2}{*}{ A 24} & $\mathrm{a}$ & 0.459 & 0.501 & -2.692 & 0.010 & A31 & 130.644 & 0.000 & 4.963 & 0.000 \\
\hline & $\mathrm{b}$ & & & -2.692 & 0.010 & & & & 4.963 & 0.000 \\
\hline \multirow[t]{2}{*}{ A41 } & $\mathrm{a}$ & 89.119 & 0.000 & 5.222 & 0.000 & A42 & 168.056 & 0.000 & 4.665 & 0.000 \\
\hline & $\mathrm{b}$ & & & 5.222 & 0.000 & & & & 4.665 & 0.000 \\
\hline \multirow[t]{2}{*}{ A43 } & $\mathrm{a}$ & 150.567 & 0.000 & 4.479 & 0.000 & A44 & 51.690 & 0.000 & 7.039 & 0.000 \\
\hline & $\mathrm{b}$ & & & 4.479 & 0.000 & & & & 7.039 & 0.000 \\
\hline \multirow[t]{2}{*}{ A51 } & $\mathrm{a}$ & 89.119 & 0.000 & 5.222 & 0.000 & A52 & 38.849 & 0.000 & 6.845 & 0.000 \\
\hline & $\mathrm{b}$ & & & 5.222 & 0.000 & & & & 6.845 & 0.000 \\
\hline \multirow[t]{2}{*}{ A53 } & $\mathrm{a}$ & 89.119 & 0.000 & 5.222 & 0.000 & A54 & 1.757 & .191 & 7.050 & 0.000 \\
\hline & b & & & 5.222 & 0.000 & & & & 7.050 & 0.000 \\
\hline \multirow[t]{2}{*}{ A61 } & $\mathrm{a}$ & 39.500 & 0.000 & 3.057 & 0.004 & A62 & 90.898 & 0.000 & 9.061 & 0.000 \\
\hline & $\mathrm{b}$ & & & 3.057 & 0.005 & & & & 9.061 & 0.000 \\
\hline \multirow[t]{2}{*}{ A63 } & $\mathrm{a}$ & 118.885 & 0.000 & 11.078 & 0.000 & A71 & 52.946 & 0.000 & 6.429 & 0.000 \\
\hline & $\mathrm{b}$ & & & 11.078 & 0.000 & & & & 6.429 & 0.000 \\
\hline \multirow[t]{2}{*}{ B72 } & $\mathrm{a}$ & 77.958 & 0.000 & 7.590 & 0.000 & A73 & 112.558 & 0.000 & 4.900 & 0.000 \\
\hline & $\mathrm{b}$ & & & 7.590 & 0.000 & & & & 4.900 & 0.000 \\
\hline \multirow[t]{4}{*}{ A 81} & $\mathrm{a}$ & 69.178 & 0.000 & 5.571 & 0.000 & A 82 & 52.946 & 0.000 & 5.952 & 0.000 \\
\hline & $\mathrm{b}$ & & & 5.571 & 0.000 & & & & 5.952 & 0.000 \\
\hline & $\mathrm{a}$ & 89.119 & 0.000 & 5.222 & 0.000 & & & & & \\
\hline & $\mathrm{b}$ & & & 5.222 & 0.000 & & & & & \\
\hline
\end{tabular}

Note: $a$ is represent equal variance assumed; $b$ is represent equal variance not assumed. 
As we can see from Table 2, the items' (A11-A83)value of " $\mathrm{t}$ " are significant. The preliminary scaling table about inner social capital in technology innovation teams has discrimination. It can reflect the different respondents' reaction. Items' (A24 and A61) level of significance is a bit poor, but they are still significant, so all the items are kept temporarily.

\subsection{Validity Analysis}

The Validity of preliminary scaling table about inner social capital in technology innovation teams is checked by factor analysis. Churchin (1979) points out that before the factor analysis, items' purification should be done to eliminate "garbage items ". The method of corrected item total correlation (CITC) and Cronbach $\alpha$ are used to do the purification. If the value of CITC is less than 0.5, the item should be deleted. Before or after doing this, Cronbach $\alpha$ should be recalculated. From table 3, we can see that the items' (A24, A44, A54 and A61) value are less than 0.5. After deleting them, the value of remaining items' CITC are more than 0.5 . The value of $\alpha$ is a little more higher than before, so keep all the remaining items and do the test of structure validity.

Table 3. The value of items' CITC and a

\begin{tabular}{cccc}
\hline items & CITC: Before deleted & CITC: After deleted & $\alpha$ \\
\hline A11 & 0.679 & 0.659 & \\
A12 & 0.641 & 0.661 & \\
A13 & 0.777 & 0.763 & \\
A21 & 0.815 & 0.835 & \\
A22 & 0.814 & 0.827 & \\
A23 & 0.799 & delete & Before deleted $\alpha=0.936$ \\
A24 & 0.405 & 0.829 & \\
A31 & 0.722 & 0.749 & \\
A41 & 0.887 & 0.901 & \\
A42 & 0.886 & 0.885 & \\
A43 & 0.88 & 0.915 & \\
A44 & -0.288 & delete & \\
A51 & 0.774 & 0.771 & \\
A52 & 0.804 & 0.829 & \\
A53 & 0.781 & 0.807 & \\
A54 & -0.208 & delete & \\
A61 & 0.211 & delete & \\
A62 & 0.681 & 0.706 & \\
A63 & 0.56 & 0.575 & After deleted $\alpha=0.972$ \\
A71 & 0.759 & 0.786 & \\
A72 & 0.711 & 0.749 & \\
A73 & 0.847 & 0.876 & \\
A81 & 0.765 & 0.793 & \\
A82 & 0.821 & 0.848 & \\
A83 & 0.827 & 0.821 & \\
\hline
\end{tabular}

The principal component analysis is used to do the factor analysis. Using the steep plot and cumulative rate of variance to determine the number of the factors and the method of Varimax is used to rotate the factors. The value of KMO is 0.855 . The approximate chi-square of Bartlett' test of sphericity is significant at the level of 0.001 . The cumulative rate of variance is $78.84 \%$. The load of each factor can be seen in table 4 . But the load of items(A41, A71, A72 and A81) are more than 05 on two components, and the phenomenon of cross load is relatively serious, so the four items should be deleted. The method above will be used again to do factor analysis. 
Table 4. The first factor analysis-factors' load after rotating

\begin{tabular}{cccc}
\hline & \multicolumn{3}{c}{ Components } \\
\cline { 2 - 4 } Items & 1 & 2 & 3 \\
\hline A11 & & 0.903 & \\
A12 & & 0.766 & \\
A13 & & 0.813 & \\
A21 & 0.729 & & \\
A22 & 0.791 & & \\
A23 & 0.708 & & \\
A31 & 0.705 & & \\
A41 & 0.758 & 0.53 & \\
A42 & 0.873 & & \\
A43 & 0.853 & & \\
A51 & 0.682 & & \\
A52 & 0.842 & & \\
A53 & 0.714 & & \\
A62 & & & 0.707 \\
A63 & & & 0.859 \\
A71 & 0.632 & & 0.572 \\
A72 & 0.617 & & 0.586 \\
A73 & 0.791 & & \\
A81 & 0.628 & & 0.547 \\
A82 & 0.828 & & \\
A83 & 0.727 & & \\
\hline
\end{tabular}

Note: Only the values of load more than 0.5 are shown.

After redoing the factor analysis, the value of KMO is 0.847 , the approximate chi-square of Bartlett' test of sphericity is significant at the level of 0.001 . Three factors are extracted; the cumulative rate of variance is $79.88 \%$, the load of each factor can be seen in table 5. Scaling table shows the structure of three factors. But the phenomenon of cross load on item (A23) is relatively serious, so the item should be deleted. The method above will be used the third time to do factor analysis.

Table 5. The second factor analysis-factors' load after rotating

\begin{tabular}{cccc}
\hline Items & \multicolumn{3}{c}{ components } \\
\cline { 2 - 4 } & 1 & 2 & 3 \\
\hline A11 & \multicolumn{3}{c}{0.888} \\
A12 & & 0.77 & \\
A13 & & 0.823 & \\
A21 & 0.747 & & \\
A22 & 0.803 & & \\
A23 & 0.714 & 0.519 & \\
A31 & 0.717 & & \\
A42 & 0.883 & & \\
A43 & 0.863 & & \\
A51 & 0.712 & & \\
A52 & 0.85 & & \\
A53 & 0.744 & & \\
A62 & & & 0.71 \\
A63 & & & 0.876 \\
A73 & 0.814 & & \\
A82 & 0.844 & & \\
A83 & 0.76 & & \\
\hline
\end{tabular}

Note: Only the values of load more than 0.5 are shown. 
After doing the factor analysis for the third time, the value of KMO is 0.830 , which is lower than the first two time, The approximate chi-square of Bartlett' test of sphericity is significant at the level of 0.001 . It is very suitable to do factor analysis. Three factors are extracted. The cumulative rate of variance is $80.16 \%$, which is higher than the first two time. The value of factor variance extracted is from 0.64 to 0.91 , explaining most part of items' information can be kept. Scaling table shows clear structure of three factors. The load of each factor can be seen in Table 6. The names of factor 2 and 3 are clear, named connection state, expectations and reciprocity respectively. Factor 1 has high load on center of network, teams' stability, leader trust, members trust, shared language and shared goal. According to the research of organizations' trust, the trust of organization from the staff will partly transfer to the leader, that is to say leader is the representative of the organization (JiangLin Ke et al, 2006). The trust and self-identity of the leader can partly transfer to the organization. As to the study in this paper, the trust of the leader and members will raise the trust of the whole team and will does good to form the center of network and teams' stability. Also, it will be helpful to the recognition of the teams' goal. The shared language, shared goal and the trust of the team belong to the whole teams' value orientation, Based on the expression of cognitive dimension by Uphoff (1996), factor 1 will be named as value orientation factor.

Table 6. The third factor analysis- factors' load after rotating

\begin{tabular}{|c|c|c|c|}
\hline \multirow{2}{*}{ Items } & \multicolumn{3}{|c|}{ component } \\
\hline & 1 & 2 & 3 \\
\hline A11 & & 0.9 & \\
\hline A12 & & 0.766 & \\
\hline A13 & & 0.83 & \\
\hline A21 & 0.752 & & \\
\hline A22 & 0.791 & & \\
\hline A31 & 0.718 & & \\
\hline A42 & 0.89 & & \\
\hline A43 & 0.866 & & \\
\hline A51 & 0.719 & & \\
\hline A52 & 0.853 & & \\
\hline A53 & 0.744 & & \\
\hline A62 & & & 0.715 \\
\hline A63 & & & 0.883 \\
\hline A73 & 0.823 & & \\
\hline A82 & 0.853 & & \\
\hline A83 & 0.778 & & \\
\hline
\end{tabular}

Note: Only the values of load more than 0.5 are shown.

\subsection{Reliability Analysis}

Reliability analysis is mainly to check the validity and consistency of the questionnaire. Reliability can be divided into internal reliability and external reliability. Internal reliability is particularly important in checking the scaling table with many options. The most commonly used method is coefficient of Cronbach $\alpha$. If the value of $\alpha$ is more than 0.9 , the reliability of the scaling table is very good, but for the minimum acceptable value of reliability, scholars have different opinions. Usually 0.7 is taken as the minimum acceptable value of reliability. In a scaling table, if it contains small tests or idea level, not only the reliability of the whole scaling table will be tested, but also the reliability of the small tests or idea level will be tested (Minglong Wu, 2003). The coefficients of Cronbach $\alpha$ are bigger than 0.7 in this paper (Table 7). Explaining that the reliability of the whole scaling table and the constructs all have good reliability.

Table 7. The value of Cronbach $\alpha$ of scaling table about inner social capital in technology innovation teams

\begin{tabular}{ccccc}
\hline & \multirow{2}{*}{ Scaling table } & \multicolumn{3}{c}{ constructs } \\
\cline { 3 - 5 } & & value orientation & connection state & expectations and reciprocity \\
\hline Value of Cronbach $\alpha$ & 0.961 & 0.969 & 0.912 & 0.789 \\
\hline
\end{tabular}




\section{Conclusions}

As the theory of social capital used widely in the organizations' management, the study of teams' social capital increases, the development of scaling table is the basis of the research about teams' social capital. Scaling table is different for different objects. In this paper, the technology innovation team is the object. The scaling table is formed by studying deeply about the theory of social capital and its wide use in the area of organizations' management especially in teams. After reviewing the literature, group discussing and depth interviewing, a scaling table including 25 items is formed. After the item analysis, validity analysis and reliability analysis are done, the scaling table including three constructs and 16 items is finally formed, which lay a certain foundation for the following empirical study.

From the final scaling table, we can see the structure of the scaling table in this paper is different with scaling tables in related research. The difference is the scaling table in this paper has less constructs. This may be related with the object in this paper. Technology innovation teams have much difference with the other teams, for example the research and development teams, top management teams in enterprise or the innovative teams in university. Especially team members are dispersed relatively, communicating with each other is not convenient, which can do adverse effect to the inner social capital of the team. When it related to the research object in this paper, the model of technology innovation team is exploratory. It exists for only a year, which can influence the social capital, but all of these are needed to be tested by the practice. By the way, this paper only does the development of scaling table about inner social capital in technology innovation teams. Its development of scaling table about outer social capital is the other important aspect.

\section{Acknowledgments}

The paper is sponsored by project: The integration of agricultural industrial chain and technology chain in Sichuan province.

\section{References}

Adler, S., \& Kwon, S. (2002). Social Capital: Prospects for a New Concept. Academy of Management Review, 27(1),17-40. http://dx.doi.org/10.5465/AMR.2002.5922314

Brown, Tomas Ford. (1999). Theoretical Summary of Social Capital. Working paper. University of Wisconsin.

Can, P., \& Li, J. (2011). Study on Measurement Index System for Teams External Social Capital. Technology Economics, 7, 48-50.

Cohen, D., \& Prusak, L. (2001). In Good Company, How social capital makes organizations work, Boston, Ma: Harvard Business School Press.

Fanghua, Z. (2006). The relations between social capital and knowledge acquisition in knowledge-based enterprise-based on the the empirical analysis of BP neural network model. The research of science, 2, 106-111.

Fangrong, H. (2003). Knowledge sharing and new product development performance-social capital perspective. $A$ thesis submitted to National kaohsiung first university of science and technology for the degree of master, 5.

Francis, F. (1995). Trust: The Social Virtues and the Creation of Prosperity. New York: Free Press.

Granovetter, M. S. (1992). Problem of explanation in economic sociology. In Nohria N. \& Eeeles R. (Eds.), Networks and organizations: Structure, form and action, Boston: Harvard Business School Press.

Hongming, X., Cheng, W., \& Yechun, W. (2007). The influence of Inner social capital on the energy of knowledge and the organizations' innovation-the empirical research of enterprises in south China. Journal of management, 1,100-107.

Jiaji, F. (1998). Technology innovation. Beijing: Qinghua university press.

Jianglin, K., Jianmin, S., Jintao, S., \& Qinxuan, G. (2007). The empirical research of relation between Enterprises' R\&D teams' social capital and the performance-with the knowledge shared and knowledge integration as mediation. Management world, 3, 89-101.

Jianglin, K., Jintao, S., \& Jianmin, S. (2007). The development of dimensions and structure test of teams' social capital. The research of science, 10, 935-940.

Jianglin, K., Xiaotao, Z., \& Jintao, S. (2006). The development of scaling table about social capital in teams and the test of its reliability and validity. Contemporary finance and economics, 12, 63-66.

Jiangqiu, W. (2009).The research review about organizations' management based on the theory of social capital. 
The guide of economic research, 23, 1-2.

Jun, Y., \& Bin, Z. (2010). The research of innovation management based on the view of social capital. Science and technology progress and countermeasures, 8, 29-31.

Leana, Van Buren. (1999). Organizational social capital and employment practices. Academy of Management Review, 24(3), 538-555. http://dx.doi.org/10.2307/259141

Mansfied, E. (1971). The Economics of Technological Change, New York. W. W. Norton and Company.

Minglong, Wu. (2003). SPSS statistical application and practice. Science press.

Mingqing, Qin. (2010).The research of the social capital in teams' influence on the new enterprises' growth in technology start-up enterprises. A master's degree in southern Jiangnan university, 12.

Na, Z., \& Xuezhong, C. (2007). Teams' social capital and its influence to the performance. The science and the management of science, 11,181-185.

Nahapiet. J., \& Ghoshal, S. (1998). Social capital, intellectual capital and the organizational advantage. Academy of Management Review, 23(2), 242-266. http://dx.doi.org/10.2307/259373

Robert, Putnam. (2001). Making Democracy Work. Princeton University Press.

Tsai, W., \& Ghoshal, S. (1998). Social capital and value creation: The role of intrafirm networks. Academy of Management Journal, 41(4), 464-476. http://dx.doi.org/10.2307/257085

Turner, Jonathan H. (1999). The Formation of Social Capital. In Social Capital: A Multifaceted Perspective, (eds.) by Partha Dagupta \& Ismail Serageldin, Washington, DC: The World Bank.

Uphoff, Norman T. (1996). Learning from Galoya: Possibilities for Participatory Development and Post-Newtonian Social Science. London: Intermediate Technology Publications.

Wayne, Baker. (2000). Achieving Success through Social Capital: tapping the hidden resources in your personal and business networks. San Francisco: Jossey-Bass.

Wenhong, Zhang. (2003). Social capital: theory argue and experience study. Sociological research, 4, 23-35.

Wenhong, Zhang. (2011). The research of China's social network and social capital for 30 years (the first part), Journal of sea, 3, 104-112.

Woolcock, M., \& Narayan, D. (2000). Social capital: Implications for development theory, research and policy. World Bank Research Observer, 15, 225- 250. http://dx.doi.org/10.1093/wbro/15.2.225

Xielin, Liu. (1993). Technology innovation economics. Beijing: China's economic press.

Yanjie, Bian, \& HaiXiong, Qiu. (2000). Social capital in enterprise and its efficiency. China social science, 2, 87-99.

Yanjie, Bian. (2006). Social capital research. Academic and research, 2, 39-40.

Yiming, Lin. (2001). The effect of team-oriented human resource management practices team knowledge sharing and innovation-the mediating role of social capital. A thesis submitted to soochow university for the degree of master, 2003, 5 . 